\title{
A simple and effective method to evaluate peak flowmeters
}

\author{
LIMAN WANG MD, MELVA PROUDLOCK RRT, MINGYAO LIU MD \\ Department of Respiratory Therapy, Peel Memorial Hospital, Brampton, and \\ The Hospital for Sick Children Research Institute, Department of Pediatrics, \\ University of Toronto, Toronto, Ontario
}

\section{WAng, M Proudlock, M LiU. A simple and effective method to evaluate peak flowmeters. Can Respir J 1996;3(2):125-129.}

OBJECTIVE: Peak flowmeters have been widely used to monitor the course of asthma. The objective of this study was to develop a simple, convenient and effective method to evaluate these devices routinely.

METHODS: A rubber band-driven $3 \mathrm{~L}$ syringe was used to generate airflows, and a pneumotachometer was connected in series with the peak flowmeter as a standard. Waveforms were recorded and compared with maximal expiratory curves. The accuracy of peak flowmeters was analyzed by linear regression and by calculating the percentage of the difference measured by the flowmeter $(\mathrm{F})$ and the pneumotachometer $(\mathrm{P})$, expressed as $(\mathrm{F}-\mathrm{P}) / \mathrm{P}(\%)$.

RESULTS: This set-up generated waveforms similar to the initial phase of maximal expiratory curves, with linear increment of peak flow rates up to $790 \mathrm{~L} / \mathrm{min}(\mathrm{R}=0.999$, $\mathrm{P}<0.001)$. Both waveforms and peak flow rates were highly reproducible with coefficients of variation less than $5 \%$ throughout the full range tested. Fourteen peak flowmeters from seven different models were evaluated. Most of these devices revealed a satisfactory linear relationship with the pneumotachometer. The interdevice variation of different models and variations of each device at different flow rates were clearly demonstrated by $(\mathrm{F}-\mathrm{P}) / \mathrm{P}(\%)$.

CONCLUSION: The system developed in the present study can be easily set up and used to evaluate the performance of peak flowmeters.

\section{Une méthode simple et efficace pour évaluer les débitmètres de pointe}

OBJECTIF : Les débitmètres de pointe sont communément utilisés pour surveiller l'évolution de l'asthme. L'objectif de cette étude était de développer une méthode efficace, pratique et simple pour procéder à une évaluation de routine de ces appareils.

METHODES : On a utilisé une seringue de 3 L commandée par un élastique pour générer des débits aériens, et un pneumotachomètre a été connecté en série avec le débitmètre de pointe comme valeur de référence. Les courbes générées ont été enregistrées et comparées aux courbes expiratoires de pointe. L'exactitude des débitmètres de pointe a été analysée par régression linéaire et en calculant le pourcentage de la différence mesurée par le débitmètre (D) et le pneumotachomètre $(\mathrm{P})$, exprimée comme $(\mathrm{D}-\mathrm{P}) / \mathrm{P}(\%)$.

RÉSULTATS : Ce montage a généré des courbes similaires à la phase initiale des courbes expiratoires de pointe avec des augmentations linéaires des débits de pointe jusqu'à $790 \mathrm{~L} /$ minute $(\mathrm{R}=0,999, \mathrm{P}<0,001)$. Les courbes ainsi que les débits de pointe démontraient une grande reproductibilité avec des coefficients de variation inférieurs à $5 \%$ pour la fourchette des débits testés. Quatorze débitmètres de pointe de 7 modèles différents ont été évalués. La plupart de ces appareils ont démontré une relation linéaire satisfaisante avec le pneumotachomètre. La variation observée entre les appareils de différents modèles et les variations propres à chaque appareil à des débits aériens différents ont été clairement démontrées par (D-P)/P (\%). CONCLUSION : Le système mis au point dans la présente étude peut facilement être monté et utilisé pour évaluer la performance des débitmètres de pointe.

Key Words: Asthma, Peak expiratory flow

Correspondence and reprints: Dr Mingyao Liu, Neonatology Research Division, The Hospital for Sick Children, 555 University Avenue, Toronto, Ontario M5G 1X8. Telephone 416-813-5491, fax 416-813-5002 
$\mathrm{P}$ eak flowmeters are commonly used in hospitals, in asthma clinics, and at home by physicians and patients to monitor the course of asthma, to identify its provocative factors, and to determine the bronchodilator or steroid responses in asthma and other chronic obstructive pulmonary diseases (1). Since Wright and McKerrow first reported the use of a peak flowmeter in 1959 (2), a number of simple, inexpensive and portable peak flowmeters have become available. It is important to have accurate, reproducible and reliable instruments for objective measurements, but some studies have indicated that there are variations among peak flowmeters, as well as some technical difficulties in maintaining these devices (3-6).

The initial calibration of the Wright peak flowmeter was based on an empirical comparison between the readings of the peak flowmeter and that of the pneumotachograph, which was obtained by asking subjects to blow alternately into each device (2). There have been several reports in the literature comparing new peak flowmeters with the original Wright peak flowmeter in this manner (7-11). Given the variation in flow rates between forced exhalation, this strategy is unsatisfactory for quantitative evaluation. Recently, the National Asthma Education Program (NAEP) sponsored by the National Heart, Lung, and Blood Institute in the United States set up a panel to make recommendations concerning technical standards and testing methods for peak flowmeters. As a result, a specific method has been developed by using a highly accurate rolling-seal spirometer system as a standard to compare performance of peak flowmeters with a computer-controlled testing syringe that generates nine multiples of American Thoracic Society waveform 24 (6). This system has been used by manufacturers to validate their products (1). However, this system is relatively expensive and thus not practical for routine use. Alternatively, the pneumotachometer has been used to validate peak flowmeters, by using either a special lung simulator (3) or a syringe manipulated manually to generate waveforms (4), or by asking normal subjects to blow through the pneumotachometer/peak flowmeter assembly with various efforts $(5,12)$. The application of these methods to monitor routinely the performance of peak flowmeters, however, is limited by requiring either special equipment, with difficulty in obtaining reproducible airflows, or a relatively large population of normal subjects and patients as volunteers.

In the present study, we used a rubber band to drive a calibrated $3 \mathrm{~L}$ syringe, generating a waveform that was similar to most maximal expiratory curves observed clinically, and evaluated 12 peak flowmeters from seven models. This setup is simple and effective. The advantages and limitations of using a pneumotachometer to validate peak flowmeters are also discussed.

\section{MATERIALS AND METHODS}

Apparatus: A screen pneumotachometer (WE Collins Inc, Massachusetts) was first calibrated following a standard procedure with a 3 L syringe (Model \#5530, Hans Rudolph Inc,

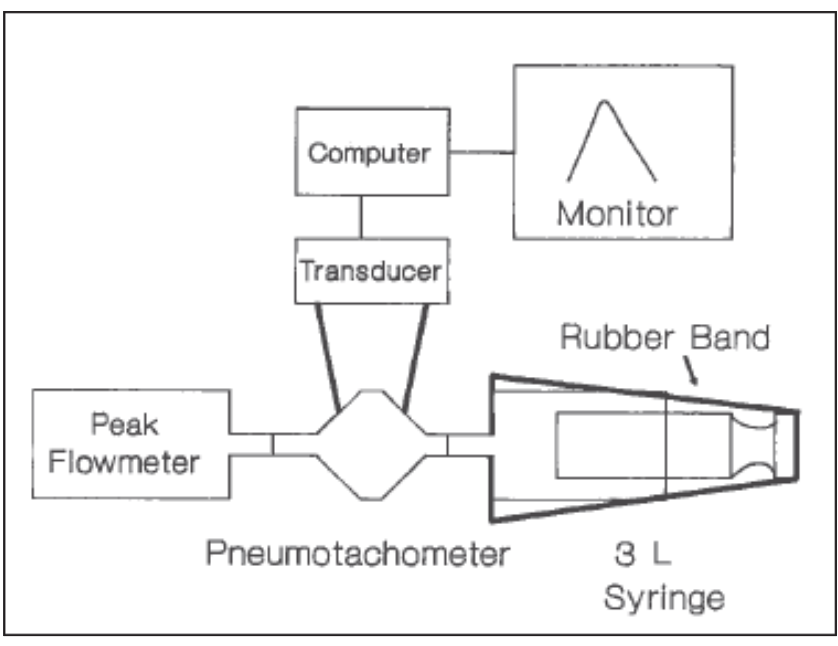

Figure 1) Schematic diagram of the set-up used to evaluate peak flowmeters. Airflows were generated by a rubber band-driven $3 \mathrm{~L}$ syringe. The peak flow rates were measured by the peak flowmeter to be tested and a pneumotachometer, connected in series as a standard

Missouri). The flow rate through the assembly was measured by a differential pressure transducer and a carrier demodulator (WE Collins Inc). The outputs were digitized and recorded by a microcomputer. The injected volume was confirmed by integrating airflow to volume. After the calibration, the peak flowmeter to be tested was connected in series with the distal end of the pneumotachometer. The mouthpiece of the flowmeter was $5 \mathrm{~cm}$ from the site of flow measurement on the pneumotachometer. The assembly was connected to the $3 \mathrm{~L}$ syringe again. A $1.0 \mathrm{~m}$ baggage rubber band (Home Hardware Co) was attached to the outlet end of the syringe's cylinder and placed over the piston of the syringe (Figure 1). To generate different peak flow rates, the piston was precisely preset at various positions, and the designated volume of air was injected into the pneumotachometer/peak flowmeter assembly instantly by releasing the rubber band. Waveforms generated were demonstrated on the screen of the computer's monitor and saved as computer files. The readings of peak flowmeters were recorded by a subject without knowing the pneumotachometer values. The results in the computer were retrieved for data analysis. Protocol and data analysis: Seven models of peak flowmeters were evaluated: PocketPeak (DeVilbiss); PulmoGraph (high range only; DeVilbiss); MiniBell (Avion); FDE WrightPocket (FDE Ferraris Medical Inc, New York); Assess (Healthscan, New Jersey); MiniWright (Clement Clarke International, Ohio); and MultiSpiro (low range only; Multispiro, Arizona). A high range (0 to $700 \mathrm{~L} / \mathrm{min})$ and a low range (0 to $400 \mathrm{~L} / \mathrm{min}$ ) device were tested for each model. All devices tested were new. The volumes of the $3 \mathrm{~L}$ syringe were preset at $0.1,0.5,0.8$ and $1.2 \mathrm{~L}$ when low range flowmeters were tested. The preset injection volumes of the syringe were extended up to 2 and $2.3 \mathrm{~L}$, when high range devices were tested. At each preset injection volume, six measurements were repeated for each device.

To test the accuracy of peak flowmeters, different peak 


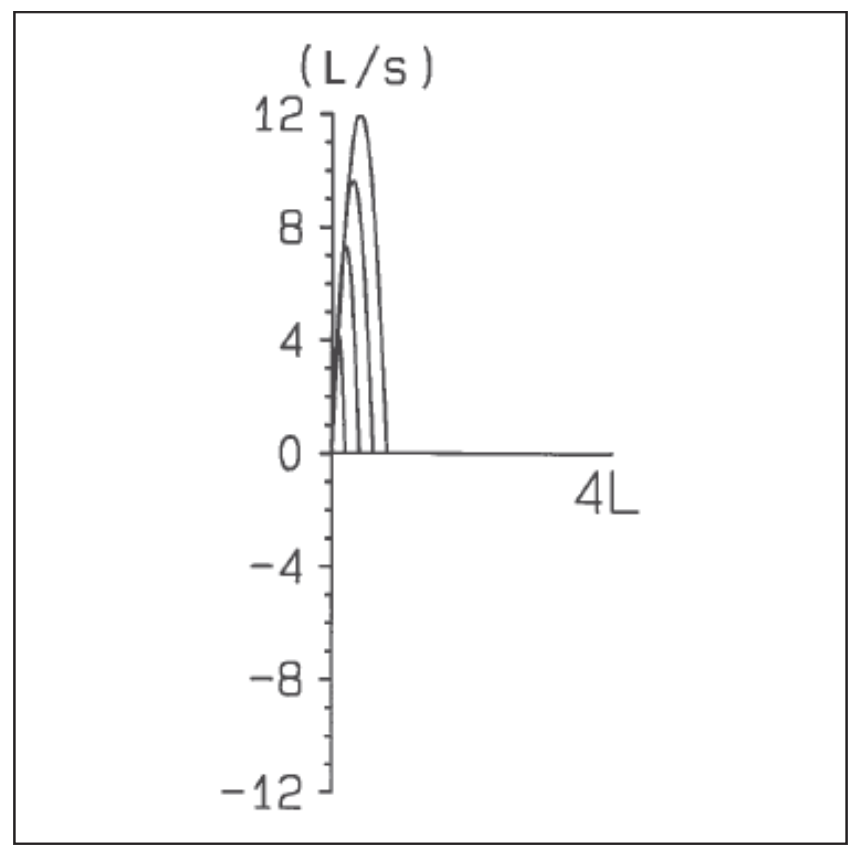

Figure 2) Flow/volume curves generated by the rubber banddriven syringe. The $3 \mathrm{~L}$ syringe was preset at $0.2,0.4,0.6$ and $0.8 \mathrm{~L}$. Peak flow rates measured by the pneumotachometer were plotted as functions of the injected volume and composed by the computer. A linear increase of flow rates was observed

flow rates were generated randomly by altering preset injection volumes. All the individual data points were included to compare readings of the peak flowmeter and the pneumotachometer with linear regression analysis. The differences of readings between the peak flowmeter $(\mathrm{F})$ and the pneumotachometer $(\mathrm{P})$ were calculated and expressed as percentages of the pneumotachometer reading, (F-P)/P (\%). Mean values of six measurements were plotted as functions of preset injection volumes. Statistical analysis was done by linear regression, Student's $t$ test or, for comparison of more than two groups, ANOVA, followed by Duncan's multiple range comparison test, with significance defined as $\mathrm{P}<0.05$.

\section{RESULTS}

The flow/volume curves generated by this set-up were similar to the initial phase of maximal expiratory curves observed clinically (Figure 2). The accuracy of the injection volumes were verified by the integration of actual injected volumes, and the flow rates increased linearly with the volumes (Figure 2). In the absence of a peak flowmeter, the rubber band-driven syringe generated peak flow rates from 135 $\mathrm{L} / \mathrm{min}$ to $790 \mathrm{~L} / \mathrm{min}$, which varied linearly with the volume of the syringe $(\mathrm{R}=0.999, \mathrm{P}<0.001$, Figure 3$)$. Coefficients of variation of peak flow rates from repetitive measurements were less than 5\% at all preset injection volumes. When peak flowmeters were connected in series with the pneumotachometer, peak flow rates through the assembly decreased slightly depending on the device tested. However, the correlation between the airflow rates, measured by the peak flow-

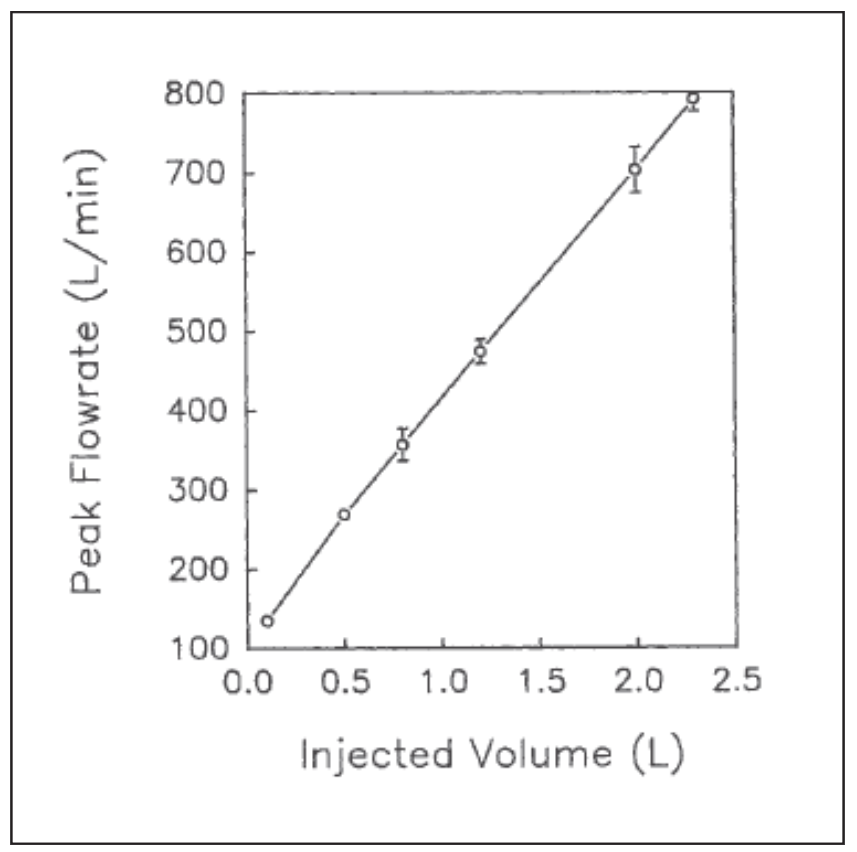

Figure 3) A linear relationship between peak flow rates read by the pneumotachometer and the injection volumes generated by the rubber band-driven syringe. The syringe was preset at 0.1, 0.5, 0.8, 1.2, 2.0 and $2.3 \mathrm{~L}$, according to pilot experiments. The peak flow rates were recorded by the pneumotachometer in the absence of a peak flowmeter. All data points are mean $\pm S D$ of six repeated measurements, plotted as functions of preset injection volumes

meter and the pneumotachometer, and the injection volumes remained linear. Flow waveforms had no distinct change (not shown).

The NAEP's standardization document requires that a peak flowmeter be accurate over its full range within $\pm 10 \%$ of readings. Readings of peak flowmeters correlated with those of the pneumotachometer were plotted. The line of identity and lines of $\pm 10 \%$ of identity were also plotted as references. Linear regression analysis revealed that most of the peak flowmeters tested were reasonably accurate. A device with expected linear correlation between the peak flowmeter readings and those of the pneumotachometer is shown in Figure 4A. A device that had lower readings (Figure 4B), and another one that had higher readings (Figure 4C) than the penumotachometer are also shown.

The correlation of peak flowmeters with the pneumotachometer was also analyzed by calculating the difference between peak flowmeter and the pneumotachometer, defined as F-P. This comparison may overestimate the difference at higher peak flow rates and underestimate the differences at lower peak flow rates. For example, when the peak flow rate was $100 \mathrm{~L} / \mathrm{min}, 20 \mathrm{~L} / \mathrm{min}$ of difference represented $20 \%$ of variation, while the same value of variation represented only $4 \%$ of variation at peak flow rate of $500 \mathrm{~L} / \mathrm{min}$, which was in the acceptable range of accuracy. Therefore, $(\mathrm{F}-\mathrm{P}) / \mathrm{P}$ was calculated as a percentage, to represent the variations between the peak flowmeter and the pneumotachometer. When this parameter is used, variations of different models can be clearly seen (Figure 5). This parameter also revealed varia- 

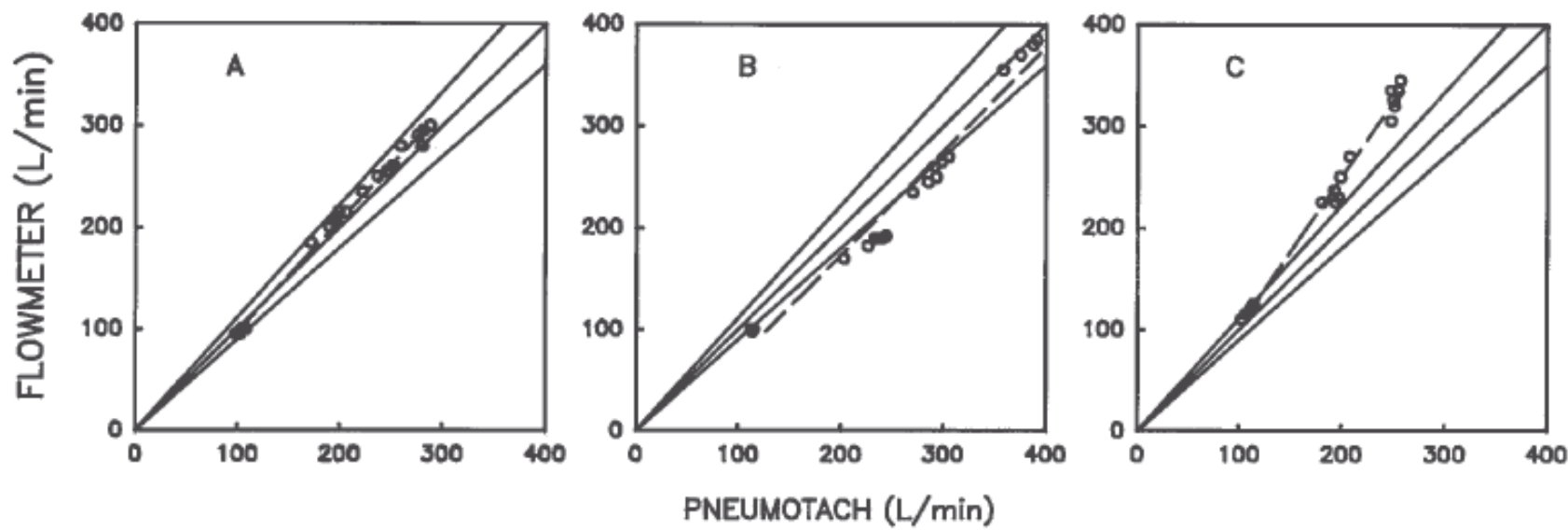

Figure 4) Accuracy of peak flowmeters analyzed by linear regression. The 3 L syringe was randomly preset at various injection volumes (from $0.1 \mathrm{~L}$ to $1.2 \mathrm{~L}$ ). Six measurements were repeated at each preset injection volume. Peak flow rates measured by the peak flowmeter were plotted as functions of readings of the pneumotachometer (pneumotach) connected in series. To assist in identifying accuracy of devices, lines of identity along with $\pm 10 \%$ of pneumotachometer values are also shown. Accuracy of each device type can be seen by reviewing where results fall within the $\pm 10 \%$ lines. Results from three low range (0 to $400 \mathrm{~L} / \mathrm{min}$ ) peak flowmeters were used to show different accuracy identified by this methods, in which one showed expected correlation with the pneumotachometer (A), one had low (B) and one had higher (C) readings than expected

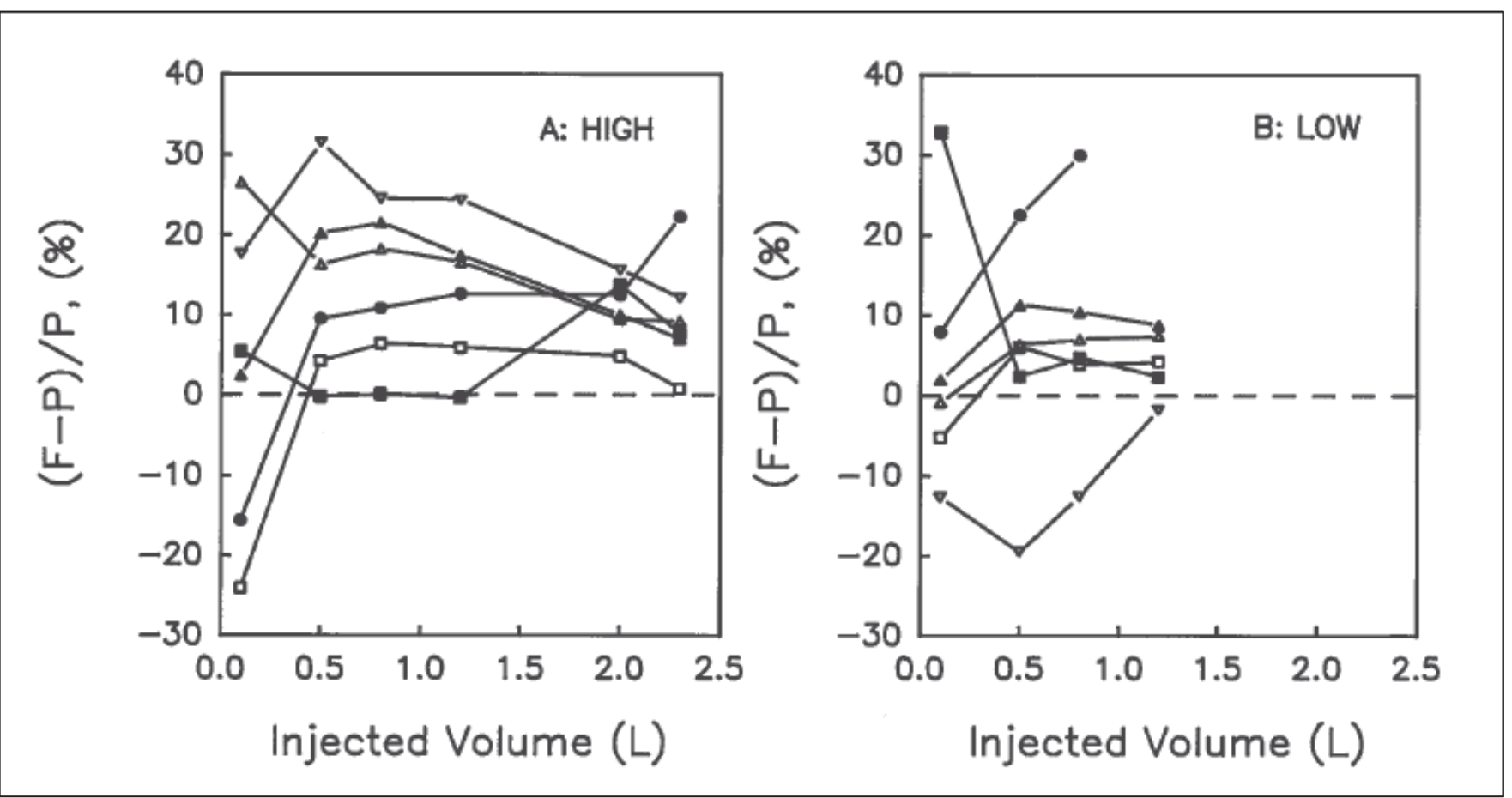

Figure 5) Summary of accuracy of devices, showing differences between the readings of the peak flowmeter $(F)$ and that of the pneumotachometer $(P)$ from the same measurement, expressed as $(F-P) / P$ in percentages. All data points are a mean of six repeated measurements, plotted as functions of preset injection volumes. A High range peak flowmeters. B Low range peak flowmeters. The symbols represent devices from different manufacturers

tions of the same device at different peak flow rates that were determined by preset injection volumes. As can be seen, although variations of some devices in the middle ranges were less then $10 \%$, they showed relatively larger variation at low or higher peak flow rates $(\mathrm{P}<0.05$, Figure 5).

\section{DISCUSSION}

Because peak flowmeters have been commonly used clinically to monitor the course of asthma, it is necessary to evaluate their performance in order to replace the inaccurate devices. In the present study, a simple set-up was developed 
to drive a $3 \mathrm{~L}$ syringe, which is routinely used in pulmonary function laboratories to calibrate the pneumotachometer, as a source for generating a set of waveforms. This method can be conveniently used to evaluate the performance of peak flowmeters. The peak flow rates can be controlled up to about $800 \mathrm{~L} / \mathrm{min}$. The $3 \mathrm{~L}$ syringe has been used manually as an airflow source to evaluate peak flowmeters by Eichenhorn and co-workers (4). These researchers had to monitor waveforms until satisfactory efforts were confirmed. Normal subjects and patients have also been used to exhale into the pneumotachometer/peak flowmeter assembly $(5,12)$. However, results may vary over a very wide range. Compared with these approaches, the rubber band-driven syringe system is simple, reproducible, efficient and can be easily set up at any pulmonary function laboratory as a reliable waveform generator for the evaluation of peak flowmeters. After repetitive measurements, the tension of the rubber band will be reduced, but it will not affect the results, because the connection of the peak flowmeter and the pneumotachometer is in series. If necessary, the rubber band can be replaced with springs and detachable adaptors.

The pneumotachometer has been used to validate the peak flowmeter since 1959 by Wright and McKerrow (2). They asked normal subjects to exhale into each device alternatively. This strategy can provide empirical data for relative comparison but not for calibration. Experiments from the present study and others suggest that connecting peak flowmeter and pneumotachometer in series is an effective way to evaluate peak flowmeters. In principle, the measurement of flow rate with the pneumotachometer requires that air flow through it evenly (13). Portable peak flowmeters depend on a calibrated spring mechanism for their reading, which yields resistance to airflow. Turbulence of airflow may occur when the peak flowmeter is connected with the pneumotachometer, especially when the flow rates are very high. However, in the treatment and monitoring of asthma, accuracy below $300 \mathrm{~L} / \mathrm{min}$ has been considered most important (5). We found that in the presence of a peak flowmeter, peak flow rates through the system decreased, but a linear relationship with the injection volumes remained. The correlation between the peak flowmeter and the pneumotachometer is very high. Therefore, using the pneumotachometer as a simple and convenient reference in asthma clinics to monitor the performance of peak flowmeters, especially within the range of $500 \mathrm{~L} / \mathrm{min}$, is practically efficient. Under certain circumstances, this set-up can be used even without the pneumotachometer. For instance, to evaluate interdevice variations from the same manufacturer, readings of different flowmeters can be compared when measured with the same injection volume. The linear range of a flowmeter can be estimated without the pneumotachometer. The accuracy of an unknown flowmeter can be estimated by comparing with a calibrated peak flowmeter if the pneumotachometer is not available.

The accuracy of peak flowmeters was estimated with two methods, linear regression analysis and the difference of the readings expressed as percentage of the pneumotachometer readings $(\mathrm{F}-\mathrm{P}) / \mathrm{P}$. The regression analysis can clearly show the linear range of each device, ie, the distribution of data points along the line of identity. The calculation of $(\mathrm{F}-\mathrm{P}) / \mathrm{P}(\%)$ is useful to demonstrate the interdevice variations and the variation of the instrument at different flow rate ranges, especially at the lower range. We did not attempt to evaluate which model of peak flowmeter is better or the best, because we tested only one device for each model at either high or low range. The interdevice variation of each model was thus not determined. Also, we did not follow the performance of these devices during long term use. Certainly, these measurements can be easily carried out after the evaluation method has been established.

\section{CONCLUSION}

We present a simple, efficient set-up using a rubber banddriven $3 \mathrm{~L}$ syringe to generate airflows and using a pneumotachometer connected in series as a standard to evaluate the performance of peak flowmeters. Within the range of peak flow rates tested, the influence of airflow resistance, generated by the peak flowmeter, did not significantly affect the performance of the pneumotachometer. However, higher airway resistance may affect the accuracy at higher range of peak flow rates. For a given accuracy, devices with lower resistances are preferred. Using (F-P)/P as an indicator, the variations among different devices or the accuracy of each device at different flow rates can be easily demonstrated and compared.

ACKNOWLEDGEMENTS: We are thankful for the collaboration from the staff in the Asthma Education Clinic and the Department of Respiratory Therapy at the Peel Memorial Hospital in Brampton. M Liu is supported by an operating grant from the Ontario Thoracic Society and by a Dean's fund from the Faculty of Medicine, University of Toronto. We thank Drs A Slutsky, AC Bryan and M Post for critically reading the manuscript.

\section{REFERENCES}

1. Hegewald MJ, Crapo RO, Jensen RL. Intraindividual peak flow variability. Chest 1995;107:156-61.

2. Wright BM, McKerrow CB. Maximum forced expiratory flow rate as a measure of ventilatory capacity. BMJ 1959;ii:1041-7.

3. Chiaramonte LT, Prabhu LP. Comparative evaluation of five peak flow devices. J Allergy Clin Immunol 1982;69:509-15.

4. Eichenhorn MS, Beauchamp RK, Harper PA, Ward JC. An assessment of three portable peak flow meters. Chest 1982;82:306-9.

5. Shapiro SM, Hendler JM, Ogirala RG, Aldrich TK, Shapiro MB. An evaluation of the accuracy of Assess and MiniWright peak flowmeters. Chest 1991;99:358-62.

6. Gardner RM, Crapo RO, Jackson BR, Jensen RL. Evaluation of accuracy and reproducibility of peak flowmeters at 1,400 $\mathrm{m}$. Chest 1992;101:948-52.

7. Brown LA, Sly RM. Comparison of mini-Wright and standard Wright peak flow meters. Ann Allergy 1980;45:72-4.

8. Darden MD, Sly RM. Evaluation of Healthscan Assess peak flow meters. Ann Allergy 1985;54:486-8.

9. Harm DL, Kotses H, Creer TL. Portable peak-flow meters: intrasubject comparisons. J Asthma 1984;21:9-13.

10. Perks WH, Tams IP, Thompson DA, Prowse K. An evaluation of the mini-Wright peak flow meter. Thorax 1979;34:79-81.

11. Wright BM. A miniature Wright peak-flow meter. BMJ 1978;ii:1627-8.

12. van Schayck CP, Dompeling E, van Weel C, Folgering H, van den Hoogen HJM. Accuracy and reproducibility of the Assess peak flow meter. Eur Respir J 1990;3:338-41.

13. Sullivan WJ, Peters G, Enright PL. Pneumotachographs: theory and clinical application. Respir Care 1984;29:736-49. 


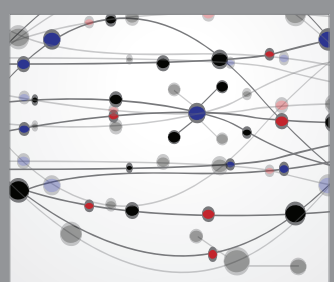

The Scientific World Journal
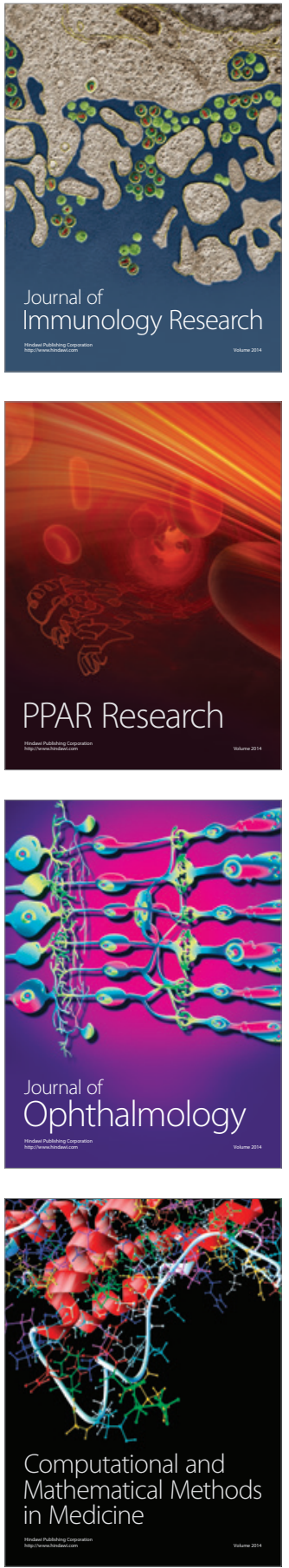

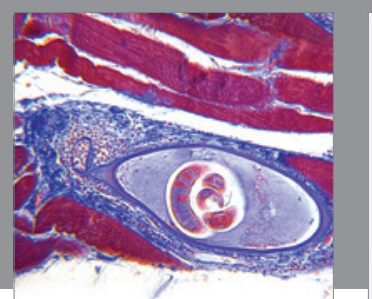

Gastroenterology Research and Practice

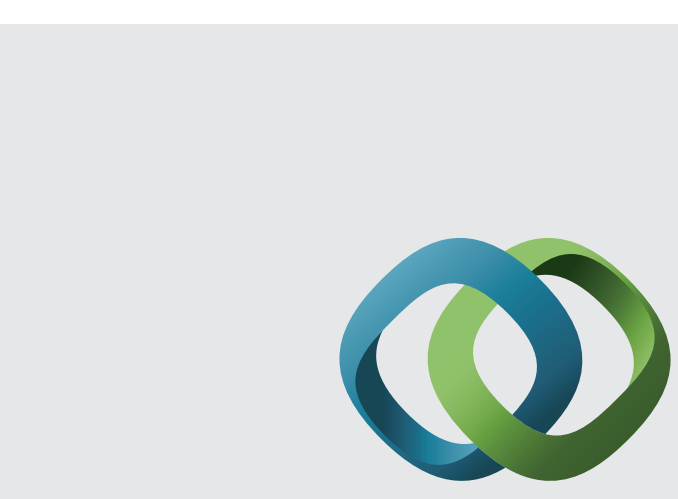

\section{Hindawi}

Submit your manuscripts at

http://www.hindawi.com
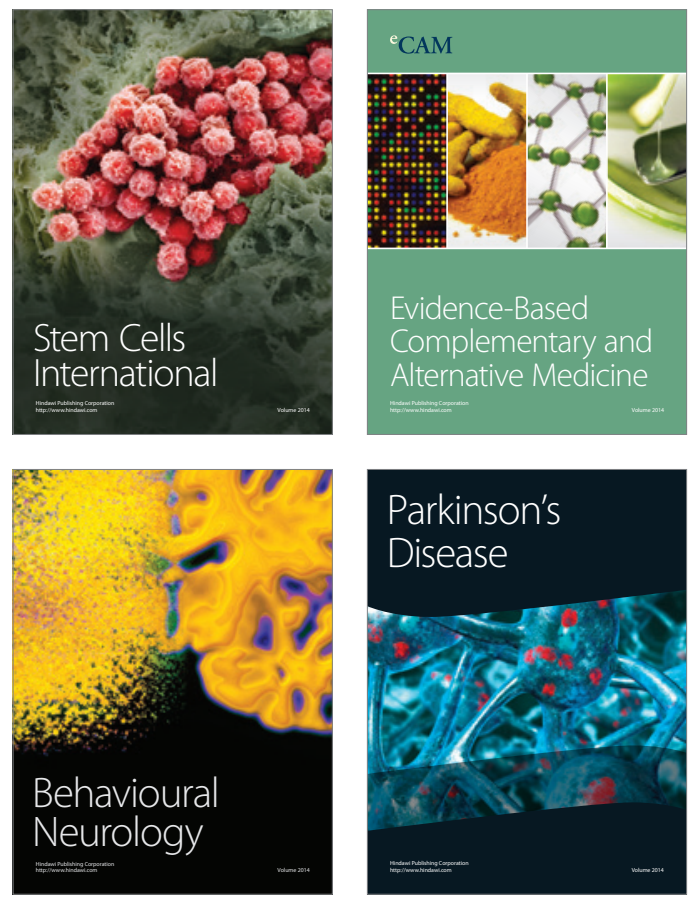
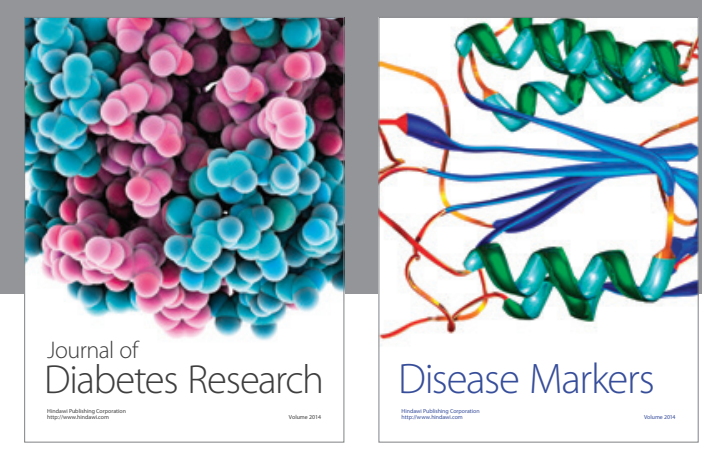

Disease Markers
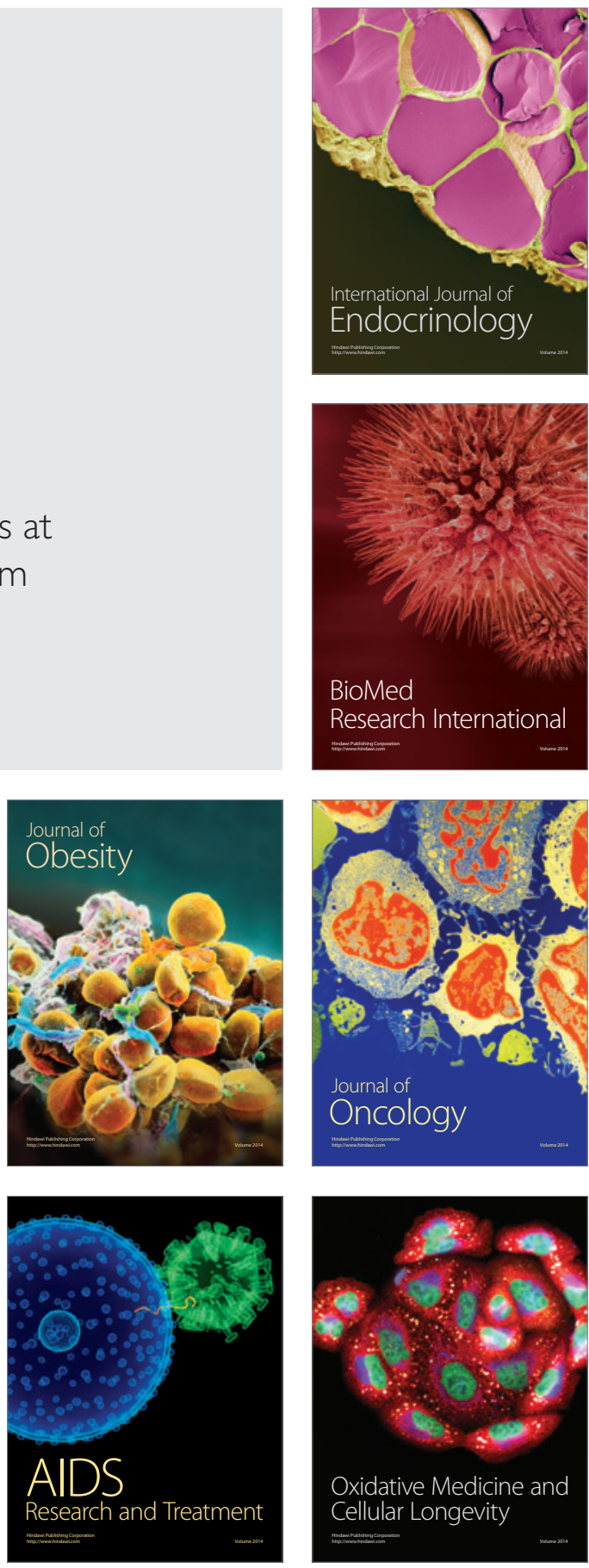